\title{
Long-Term Changes in Post-Stroke Depression, Emotional Incontinence, and Anger
}

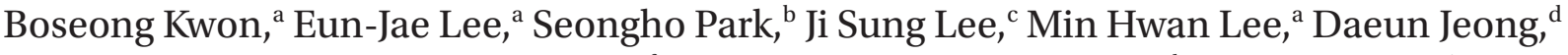 \\ Dongwhane Lee, ${ }^{\mathrm{e}, *}$ Hyuk Sung Kwon, ${ }^{\mathrm{f}}$ Dae-Il Chang, ${ }^{\mathrm{g}}$ Jong-Ho Park, ${ }^{\mathrm{h}}$ Jae-Kwan Cha, ${ }^{\mathrm{i}}$ Ji Hoe Heo, ${ }^{\mathrm{j}}$ \\ Sung-Il Sohn, ${ }^{\mathrm{k}}$ Dong-Eog Kim, ${ }^{1}$ Smi Choi-Kwon, ${ }^{\mathrm{m}}$ Jong S. Kim ${ }^{\mathrm{a}}$ \\ aDepartment of Neurology, Asan Medical Center, University of Ulsan College of Medicine, Seoul, Korea \\ bDepartment of Neurology, Inje University Haeundae Paik Hospital, Busan, Korea \\ 'Clinical Research Center, Asan Medical Center, Seoul, Korea \\ ${ }^{d}$ Department of Neurology, Veterans Health Service Medical Center, Seoul, Korea \\ 'Department of Neurology, Gachon University Gil Medical Center, Incheon, Korea \\ fDepartment of Neurology, Hanyang University Guri Hospital, Hanyang University College of Medicine, Guri, Korea \\ ${ }^{9}$ Department of Neurology, Kyung Hee University Hospital, Seoul, Korea \\ hDepartment of Neurology, Myongji Hospital, Hanyang University College of Medicine, Goyang, Korea \\ 'Department of Neurology, Dong-A University Hospital, Busan, Korea \\ 'Department of Neurology, Severance Hospital, Yonsei University College of Medicine, Seoul, Korea \\ kDepartment of Neurology, Keimyung University Dongsan Medical Center, Daegu, Korea \\ 'Department of Neurology, Dongguk University Ilsan Hospital, Goyang, Korea \\ ${ }^{m}$ College of Nursing, Seoul National University, Seoul, Korea
}

Background and Purpose Long-term changes in post-stroke depression (PSD), post-stroke emotional incontinence (PSEI), and post-stroke anger (PSA) have rarely been studied.

Methods This is a sub-study of EMOTION, a randomized, placebo-controlled trial, that examined the efficacy of escitalopram on PSD, PSEI, and PSA in patients with stroke. We interviewed patients at the long-term period (LTP) using predefined questionnaires: Montgomery-Åsberg depression rating scale (MADRS) for PSD, modified Kim's criteria for PSEl, and Spielberger trait anger scale for PSA. Additionally, the ENRICHD Social Support Instrument (ESSI) for the social support state and the modified Rankin Scale (mRS) were measured. We investigated the changes in and factors behind PSD, PSEI, and PSA at LTP.

Results A total of 222 patients were included, and the median follow-up duration was 59.5 months (interquartile range, 50 to 70). Compared to the data at 6 months post-stroke, the prevalence of PSEl (11.7\% at 6 months, $6.3 \%$ at LTP; $P=0.05)$ and mean anger score $(21.62,16.24$; $P<0.01)$ decreased, while the prevalence of PSD $(35.6 \%, 44.6 \% ; P=0.03)$ and mean MADRS $(6.16$, 8.67; $P<0.01)$ increased at LTP. ESSI was associated with PSD and PSA, but not with PSEI. The effect of the baseline National Institutes of Health Stroke Scale score on PSD decreased over time. The effect of low social support on PSD was greater than that of mRS at LTP.

Conclusions The prevalence and degree of PSD significantly increased, while those of PSEl and PSA decreased at LTP. PSD in this stage appeared to be more closely associated with a lack of social support than patients' physical disabilities.
Correspondence: Jong S. Kim Department of Neurology, Asan Medical Center, University of Ulsan College of Medicine, 88 Olympic-ro 43-gil, Songpagu, Seoul 05505, Korea Tel: +82-2-3010-3440 Fax: +82-2-474-4691 E-mail: jongskim@amc.seoul.kr https://orcid.org/0000-0002-3999-4992

Received: November 20, 2020

Revised: January 27, 2021

Accepted: February 22, 2021

*Current affiliation: Department of Neurology, Uijeongbu Eulji Medical Center, Eulji University School of Medicine, Uijeongbu, Korea

Keywords Ischemic stroke; Depression; Emotions; Anger 


\section{Introduction}

Patients with stroke often develop mood and emotional disturbances, including post-stroke depression (PSD), post-stroke emotional incontinence (PSEI), and post-stroke anger (PSA). ${ }^{1-3}$ A recent meta-analysis showed that about one-third of patients have PSD at any time within 5 years after stroke. ${ }^{4}$ The prevalence of PSEI and PSA in the early phase has been reported to be $6 \%$ to $34 \%$ and $15 \%$ to $35 \%$, respectively. ${ }^{3}$

The pathogenesis of these mood and emotional disturbances is similar, but not identical. For PSEI and PSA, serotonergic dysfunction caused by stroke lesions appears to play an important role. $^{3}$ Although this could also account for the development of PSD, the pathophysiology of PSD appears more complex because of the strong involvement of familial/psychosocial factors. ${ }^{5}$ Thus, the pathophysiology of PSD may differ according to the time point after the stroke. ${ }^{5,6}$

The prevalence of and associated factors for these disturbances in the long-term period (LTP) have been rarely studied. ${ }^{3,4}$ The aim of this study was to investigate the prevalence of and associated factors for PSD, PSEI, and PSA at LTP, using follow-up data from the Efficacy of Early Administration of Escitalopram on Depressive and Emotional Symptoms and Neurologic Dysfunction After Stroke (EMOTION) trial, a double-blind, placebo-controlled, randomized study.

\section{Methods}

\section{Study design and participants}

This is a sub-study of the EMOTION trial (ClinicalTrials.gov NCT01278498) previously performed in 17 university hospitals in South Korea. Briefly, we enrolled patients who (1) were aged $\geq 20$ years; (2) had an acute stroke within 21 days before randomization; and (3) had a modified Rankin Scale (mRS) score of $\geq 2$ at the screening stage. We excluded patients who had (1) been diagnosed with psychiatric diseases before the index stroke; (2) severe dementia or aphasia; and (3) strong suicidal thoughts. Finally, 478 patients were enrolled and randomly administered either escitalopram (10 $\mathrm{mg} /$ day) or placebo for 3 months. The outcome variables were assessed at baseline, 3, and 6 months post-stroke.

In this sub-study, we measured the long-term outcomes of PSD, PSEI, and PSA. EMOTION investigators were invited to join this sub-study. This study was approved by the Institutional Review Boards (IRBs) of the hospitals. Informed consent was obtained from all participants.

\section{Assessments}

Data obtained from EMOTION trial

Information on demographics, risk factors, and clinical and outcome variables was obtained from the EMOTION trial. Depressive symptoms were measured using the Montgomery-Åsberg depression rating scale (MADRS), ${ }^{8,9}$ and the presence of PSD was defined by MADRS $\geq 8$. 10,11 Emotional incontinence was assessed using modified Kim's criteria ${ }^{7}$ and dichotomized as "present" or "not present." Anger score was measured using the modified Spielberger trait anger-Kim's scale (Supplementary Table 1). The range of the anger score was 10 to 40 points (higher scores indicating more severe symptoms), and it was analyzed as a continuous variable in this study. We did not consider cut-off anger score for the definition of PSA. Stroke symptoms and functional deficits were evaluated using the National Institutes of Health Stroke Scale (NIHSS) ${ }^{12}$ and mRS, ${ }_{13}^{13}$ respectively.

We aimed to examine the natural course of PSD, PSEI, and PSA. As escitalopram was administered for 3 months in the EMOTION trial and the duration was considered sufficient to wash out the pharmacological effect, ${ }^{14}$ we used data at 6 months post-stroke in addition to the data obtained at LTP.

\section{Long-term follow-up assessment}

We investigated PSD, PSEI, PSA, and mRS at LTP. Additionally, social support was measured using the enhancing recovery in coronary heart disease (ENRICHD) Social Support Instrument (ESSI). This instrument measures structural, instrumental, and emotional support ${ }^{15}$ (higher scores indicating better social support). We defined "low social support" as reported previously: ${ }^{16}$ a total score of five items $(1,2,3,5$, and 6$)$ in ESSI of $<19$, and a score of $<3$ on at least any two items. We also asked the patients about the use of antidepressants and/or psychiatric clinic visits to manage their emotional problems.

\section{Statistical analysis}

Baseline variables are presented as number with percentage (\%), mean \pm standard deviation, or median with interquartile range, as appropriate. For comparison of any two independent groups, we used chi-square test, Student's t-test, or Mann-Whitney U test. We conducted a simple regression test using baseline characteristics as independent variables, and PSD, PSEI, and anger score at 6 months post-stroke and LTP as outcomes. We then performed multiple logistic regression test adjusting for important factors $(P<0.1)$ from the result of the simple regression test. The correlations between MADRS at LTP and ESSI and those between anger score at LTP and ESSI were analyzed using Spearman's rank cor- 


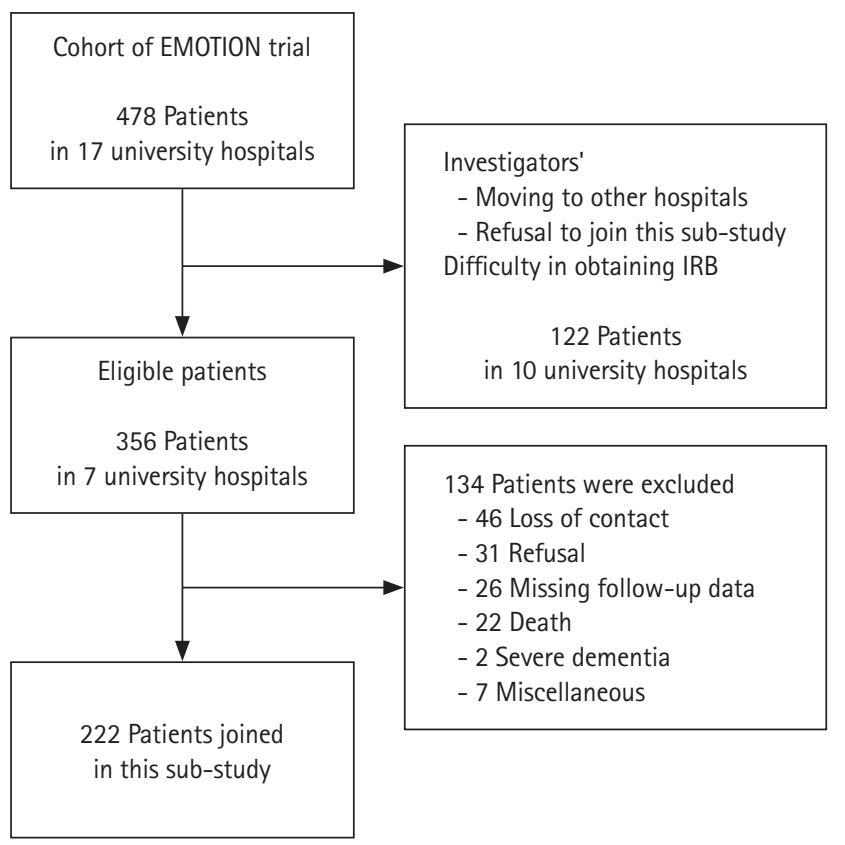

Figure 1. Study profile. EMOTION, Efficacy of Early Administration of Escitalopram on Depressive and Emotional Symptoms and Neurologic Dysfunction After Stroke; IRB, Institutional Review Board. relation coefficient. The effect of $m R$ S and ESSI on PSD at LTP was also analyzed using an adjusted logistic regression test. All statistical calculations were performed using IBM SPSS Statistics for Windows version 24.0 (IBM Co., Armonk, NY, USA) or R version 3.6.0 (R Foundation for Statistical Computing, Vienna, Austria). Statistical significance was set at $\mathbf{a}=0.05$.

\section{Results}

Seven of 17 hospitals that had previously participated in the EMOTION trial were included in this sub-study. The other centers could not perform this study because of the investigators being transferred to other hospitals, loss of interest, or practical difficulties in performing the study (e.g., IRBs allowing direct but not telephone interviews). The seven hospitals had previously enrolled 356 patients in the EMOTION trial, 222 of whom consented to participate. The major reasons for non-participation were the inability to establish contact (46 patients, 34.3\%), patients' reluctance to participate (31 patients, 23.1\%), missing data (26 patients, 19.4\%), and patients

Table 1. Baseline characteristics and clinical variables of participants and non-participants

\begin{tabular}{|c|c|c|c|}
\hline Characteristic & Participants $(n=222)$ & Non-participants $(n=134)$ & $P$ \\
\hline Age $(y r)$ & $63.0(53.0-70.0)$ & $70.5(60.0-76.0)$ & $<0.01$ \\
\hline Female sex & $86(38.7)$ & $53(39.6)$ & 0.97 \\
\hline Hypertension & $167(75.2)$ & $108(80.6)$ & 0.30 \\
\hline Diabetes & 93 (41.9) & $54(40.3)$ & 0.85 \\
\hline Hyperlipidemia & $112(50.5)$ & $80(59.7)$ & 0.11 \\
\hline Coronary artery disease & 35 (15.8) & $16(11.9)$ & 0.40 \\
\hline Smoking & $116(52.3)$ & $69(51.5)$ & 0.98 \\
\hline Family history of stroke & $58(26.1)$ & $35(26.1)$ & 1.00 \\
\hline Lesion location & & & 0.14 \\
\hline Anterior circulation & $139(62.6)$ & $83(61.9)$ & \\
\hline Posterior circulation & $77(34.7)$ & $51(38.1)$ & \\
\hline Both & $6(2.7)$ & $0(0)$ & \\
\hline Lesion side & & & 0.06 \\
\hline Right & $99(44.6)$ & $72(53.7)$ & \\
\hline Left & $107(48.2)$ & $59(44.0)$ & \\
\hline Both & $16(7.2)$ & $3(2.2)$ & \\
\hline MADRS & $9.3 \pm 8.0$ & $11.8 \pm 9.1$ & 0.01 \\
\hline PSD & $113(50.9)$ & $78(58.2)$ & 0.22 \\
\hline PSEI & $19(8.6)$ & $6(4.5)$ & 0.21 \\
\hline Anger score & $22.9 \pm 5.5$ & $23.9 \pm 5.3$ & 0.09 \\
\hline NIHSS & $4.0(3.0-7.0)$ & $5.0(3.0-7.0)$ & 0.04 \\
\hline $\mathrm{mRS}$ & $4.0(3.0-5.0)$ & $5.0(4.0-5.0)$ & 0.16 \\
\hline Non-use of escitalopram & $110(49.5)$ & $68(50.7)$ & 0.91 \\
\hline
\end{tabular}

Values are presented as median (interquartile range), number (\%), or mean \pm standard deviation.

MADRS, Montgomery-Åsberg depression rating scale; PSD, post-stroke depression; PSEl, post-stroke emotional incontinence; NIHSS, National Institutes of Health Stroke Scale; mRS, modified Rankin Scale. 


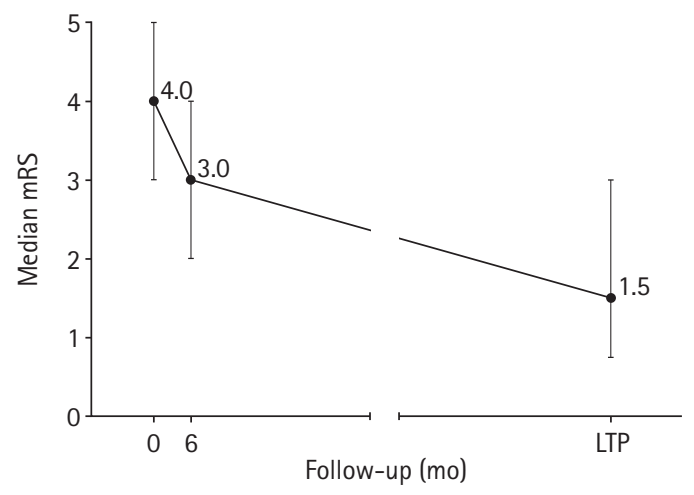

A

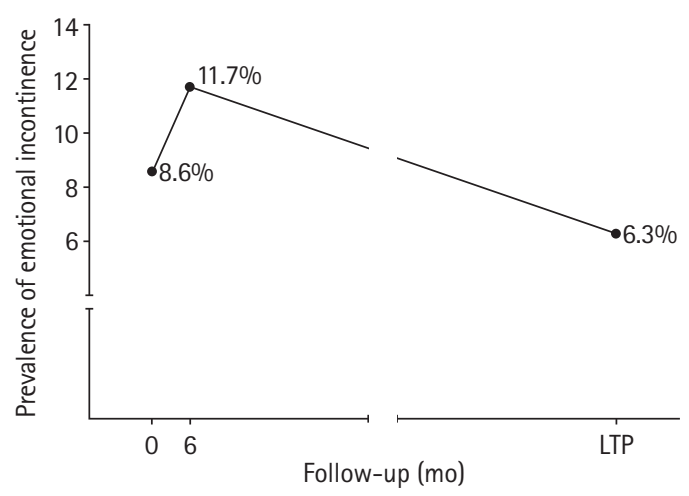

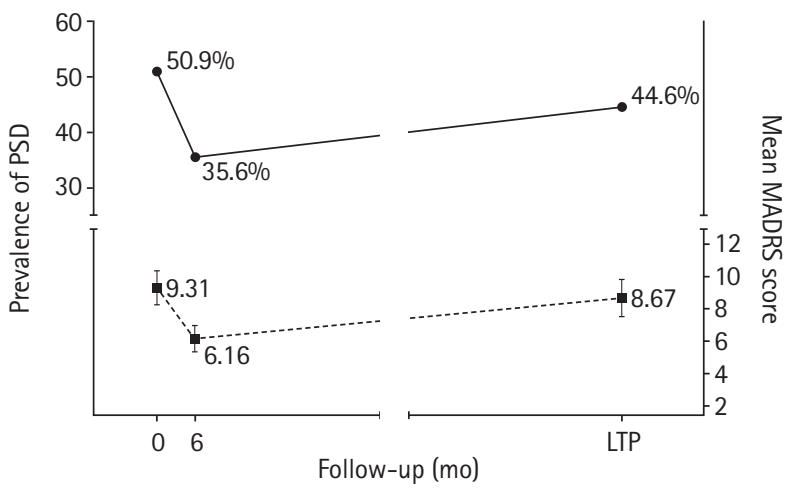

B

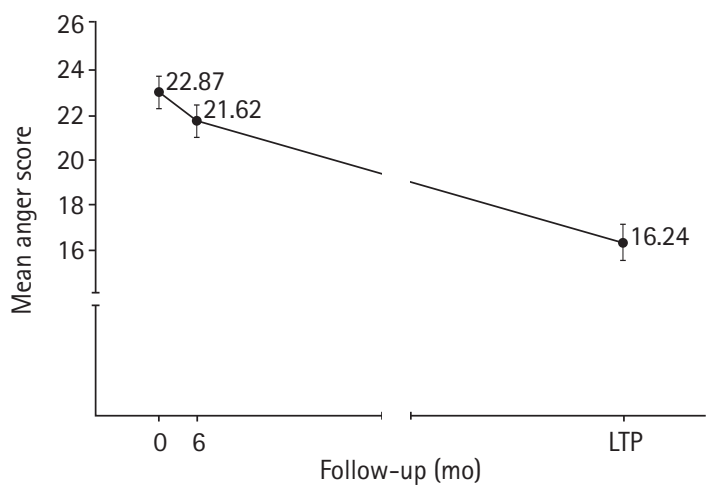

\section{C}

(D)

Figure 2. (A) Median modified Rankin Scale (mRS) with interquartile range. (B) Prevalence of post-stroke depression (PSD) and mean Montgomery-Åsberg depression rating scale (MADRS) with 95\% confidence interval (Cl). (C) Prevalence of post-stroke emotional incontinence. Follow-up time is shown in month. (D) Mean anger score with 95\% Cl. LTP, long-term period.

passing away (22 patients, 16.4\%) (Figure 1).

Fifty-one of 222 patients were interviewed face-to-face at the outpatient clinic, and the others were interviewed via telephone by a trained investigator. The investigators obtained written consent (or verbal consent on the telephone) and interviewed them using a pre-established questionnaire. If possible, relatives or caregivers were also interviewed to confirm the patient's responses. All interviews were conducted between May 2017 and May 2018.

The duration from the index stroke to LTP ranged from 35 to 83 months (60 [range, 50 to 70]). All participants lived in their homes, except for four who were in the sanitarium. Nine of 222 patients (4.1\%) experienced recurrent stroke. Twenty-nine of $222(13.0 \%)$ were taking antidepressants, and 28 (12.6\%) were regularly visiting psychiatric clinics. Of 99 patients with PSD at LTP, only $20(20.2 \%)$ were being treated. A total of 78 patients (35.1\%) had low social support. There were no significant differences in baseline characteristics between participants and non-participants, except that non-participants were older and had higher MADRS and NIHSS scores (Table 1).
Compared to the mRS 6 months post-stroke (3.0 [2.0 to 4.0]), the median mRS at LTP ( 1.50 [0.75 to 3.00], $P<0.01)$ decreased (Figure 2A), whereas the prevalence of PSD (35.6\% to $44.6 \%, P=0.03$ ) and mean MADRS (6.2 to 8.7, $P<0.01$ ) increased (Figure 2B). The prevalence of PSEI (11.7\% to 6.3\%, $P=0.05)$ and mean anger score at LTP (21.6 to $16.2, P<0.01)$ decreased (Figure 2C and D).

We studied the relationships between demographic and clinical factors, and the use of escitalopram, and PSD, PSEI, and anger score at 6 months and at LTP in a simple regression analysis (Table 2). Variables showing significant effects $(P<0.05)$ were baseline PSEl and NIHSS for PSEl at 6 months; left side lesion, baseline PSEI, and NIHSS for PSEI at LTP; and female sex, baseline anger score for PSA at both 6 months and LTP. Female sex, baseline MADRS, PSD, and NIHSS were significant factors for PSD at 6 months, while age, hyperlipidemia, baseline MADRS, PSD, and NIHSS were significantly associated with PSD at LTP.

Multiple logistic regression analysis after adjustment for important factors $(P<0.1)$ showed that the following factors were 
Table 2. Simple regression test using PSD, PSEI, and anger score as outcomes

\begin{tabular}{|c|c|c|c|c|c|c|}
\hline \multirow{2}{*}{ Variable } & \multicolumn{2}{|c|}{ PSD } & \multicolumn{2}{|l|}{ PSEI } & \multicolumn{2}{|c|}{ Anger score } \\
\hline & OR (95\% Cl) & $P$ & OR $(95 \% \mathrm{Cl})$ & $P$ & Beta $(95 \% \mathrm{Cl})$ & $P$ \\
\hline \multicolumn{7}{|l|}{ Age } \\
\hline $6 \mathrm{mo}$ & 1.00 (0.98 to 1.03$)$ & 0.78 & 0.99 (0.95 to 1.02$)$ & 0.44 & $-0.13(-0.26$ to 0.00$)$ & 0.05 \\
\hline LTP & 1.03 (1.01 to 1.05$)$ & 0.02 & 1.00 (0.95 to 1.04$)$ & 0.90 & $-0.06(-0.19$ to 0.07$)$ & 0.36 \\
\hline \multicolumn{7}{|l|}{ Female sex } \\
\hline $6 \mathrm{mo}$ & 2.16 (1.23 to 3.80$)$ & 0.01 & 1.41 (0.62 to 3.22 ) & 0.41 & $-0.16(-0.29$ to -0.03$)$ & 0.02 \\
\hline LTP & 1.67 (0.97 to 2.87 ) & 0.07 & 1.63 (0.55 to 4.83 ) & 0.38 & $-0.15(-0.28$ to -0.02$)$ & 0.03 \\
\hline \multicolumn{7}{|l|}{ Hypertension } \\
\hline $6 \mathrm{mo}$ & 1.19 (0.63 to 2.28 ) & 0.59 & 0.58 (0.24 to 1.40$)$ & 0.23 & $0.07(-0.07$ to 0.20$)$ & 0.32 \\
\hline LTP & 1.59 (0.85 to 2.98) & 0.15 & 0.82 (0.25 to 2.72 ) & 0.74 & 0.13 (0.00 to 0.26$)$ & 0.05 \\
\hline \multicolumn{7}{|l|}{ Diabetes } \\
\hline $6 \mathrm{mo}$ & 1.74 (1.00 to 3.04$)$ & 0.05 & 1.02 (0.45 to 2.33 ) & 0.96 & 0.02 (-0.11 to 0.16$)$ & 0.72 \\
\hline LTP & 1.51 (0.88 to 2.59) & 0.13 & 0.36 (0.10 to 1.32$)$ & 0.12 & $-0.03(-0.16$ to 0.10$)$ & 0.63 \\
\hline \multicolumn{7}{|l|}{ Hyperlipidemia } \\
\hline $6 \mathrm{mo}$ & 1.39 (0.80 to 2.41$)$ & 0.25 & 0.69 (0.30 to 1.58$)$ & 0.38 & $-0.05(-0.18$ to 0.08$)$ & 0.46 \\
\hline LTP & 2.45 (1.42 to 4.21$)$ & $<0.01$ & 1.33 (0.45 to 3.98) & 0.61 & $0.11(-0.02$ to 0.25$)$ & 0.09 \\
\hline \multicolumn{7}{|l|}{ Smoking } \\
\hline $6 \mathrm{mo}$ & 0.66 (0.38 to 1.15$)$ & 0.14 & 1.08 (0.47 to 2.44 ) & 0.86 & $0.09(-0.04$ to 0.23$)$ & 0.16 \\
\hline LTP & 0.76 (0.45 to 1.29 ) & 0.31 & 0.91 (0.31 to 2.68) & 0.86 & $0.13(-0.01$ to 0.26$)$ & 0.06 \\
\hline \multicolumn{7}{|l|}{ Lesion location } \\
\hline Anterior circulation & Reference & & Reference & & Reference & \\
\hline \multicolumn{7}{|l|}{ Posterior circulation } \\
\hline $6 \mathrm{mo}$ & 0.81 (0.45 to 1.43 ) & 0.46 & 0.87 (0.37 to 2.06$)$ & 0.76 & $0.01(-0.12$ to 0.14$)$ & 0.87 \\
\hline LTP & 0.92 (0.53 to 1.60$)$ & 0.78 & 0.44 (0.12 to 1.61$)$ & 0.21 & $-0.02(-0.15$ to 0.11$)$ & 0.78 \\
\hline \multicolumn{7}{|l|}{ Lesion side } \\
\hline Right side & Reference & & Reference & & Reference & \\
\hline \multicolumn{7}{|l|}{ Left side } \\
\hline $6 \mathrm{mo}$ & 0.74 (0.43 to 1.29$)$ & 0.29 & 0.93 (0.41 to 2.12) & 0.86 & $-0.03(-0.16$ to 0.10$)$ & 0.63 \\
\hline LTP & 0.65 (0.38 to 1.11$)$ & 0.11 & 0.20 (0.05 to 0.74$)$ & 0.02 & $-0.11(-0.25$ to 0.02$)$ & 0.09 \\
\hline \multicolumn{7}{|l|}{ Baseline MADRS } \\
\hline $6 \mathrm{mo}$ & 1.18 (1.12 to 1.24$)$ & $<0.01$ & 0.99 (0.94 to 1.05$)$ & 0.81 & $0.02(-0.11$ to 0.16$)$ & 0.72 \\
\hline LTP & 1.08 (1.04 to 1.12 ) & $<0.01$ & 0.99 (0.92 to 1.06$)$ & 0.72 & $0.07(-0.06$ to 0.21$)$ & 0.27 \\
\hline \multicolumn{7}{|l|}{ Baseline PSD } \\
\hline $6 \mathrm{mo}$ & 9.19 (4.68 to 18.03$)$ & $<0.01$ & 1.14 (0.50 to 2.60 ) & 0.75 & $0.03(-0.10$ to 0.17$)$ & 0.62 \\
\hline LTP & 3.50 (2.01 to 6.12 ) & $<0.01$ & 0.71 (0.24 to 2.11$)$ & 0.54 & 0.05 (-0.08 to 0.18$)$ & 0.45 \\
\hline \multicolumn{7}{|l|}{ Baseline PSEI } \\
\hline $6 \mathrm{mo}$ & 2.16 (0.84 to 5.56 ) & 0.11 & 5.65 (1.99 to 16.06$)$ & $<0.01$ & $-0.03(-0.16$ to 0.11$)$ & 0.69 \\
\hline LTP & 1.80 (0.69 to 4.66$)$ & 0.23 & 5.15 (1.44 to 18.38$)$ & 0.01 & $0.06(-0.07$ to 0.19$)$ & 0.40 \\
\hline \multicolumn{7}{|l|}{ Baseline anger score } \\
\hline $6 \mathrm{mo}$ & 1.01 (0.96 to 1.07 ) & 0.59 & 0.98 (0.91 to 1.05$)$ & 0.55 & 0.59 (0.49 to 0.70$)$ & $<0.01$ \\
\hline LTP & 1.02 (0.97 to 1.07 ) & 0.41 & 0.93 (0.84 to 1.02 ) & 0.13 & 0.23 (0.11 to 0.36 ) & $<0.01$ \\
\hline \multicolumn{7}{|l|}{ Baseline NIHSS } \\
\hline $6 \mathrm{mo}$ & 1.21 (1.09 to 1.34$)$ & $<0.01$ & 1.24 (1.09 to 1.42$)$ & $<0.01$ & $-0.03(-0.16$ to 0.11$)$ & 0.69 \\
\hline LTP & 1.14 (1.04 to 1.26$)$ & 0.01 & 1.24 (1.05 to 1.46$)$ & 0.01 & $0.11(-0.02$ to 0.25$)$ & 0.09 \\
\hline \multicolumn{7}{|c|}{ Non-use of escitalopram } \\
\hline $6 \mathrm{mo}$ & 1.35 (0.78 to 2.35 ) & 0.28 & 1.22 (0.54 to 2.76 ) & 0.64 & $0.00(-0.13$ to 0.14$)$ & 0.95 \\
\hline LTP & 1.00 (0.59 to 1.69$)$ & 0.99 & 1.39 (0.46 to 4.13$)$ & 0.56 & $-0.07(-0.20$ to 0.06$)$ & 0.28 \\
\hline
\end{tabular}

Logistic regression test for binary variables (PSD, PSEI) and linear regression test for continuous variable (anger score). Beta refers to the standardized beta coefficient of the linear regression test. The PSD, PSEl, and anger score at 6 months post-stroke were used to identify significant factors.

PSD, post-stroke depression; PSEl, post-stroke emotional incontinence; OR, odds ratio; Cl, confidence interval; LTP, long-term period; MADRS, MontgomeryÅsberg depression rating scale; NIHSS, National Institutes of Health Stroke Scale. 
Table 3. Multiple regression test using PSD, PSEl, and anger score at 6 months post-stroke and LTP as outcomes

\begin{tabular}{|c|c|c|c|c|}
\hline \multirow{2}{*}{ Variable } & \multicolumn{2}{|c|}{6 Months post-stroke } & \multicolumn{2}{|c|}{ LTP } \\
\hline & OR or beta $(95 \% \mathrm{Cl})$ & $P$ & OR or beta $(95 \% \mathrm{Cl})$ & $P$ \\
\hline \multicolumn{5}{|l|}{$\mathrm{PSD}^{*}$} \\
\hline Age (yr) & 0.97 (0.94 to 1.00$)$ & 0.07 & 1.02 (0.99 to 1.04 ) & 0.20 \\
\hline Female sex & 2.01 (1.01 to 3.98 ) & 0.05 & 1.23 (0.66 to 2.27 ) & 0.52 \\
\hline Diabetes & 1.45 (0.75 to 2.82 ) & 0.27 & 1.07 (0.59 to 1.94 ) & 0.82 \\
\hline Hyperlipidemia & 1.07 (0.55 to 2.07 ) & 0.84 & 2.22 (1.23 to 3.98$)$ & 0.01 \\
\hline Baseline PSD & 8.66 (4.23 to 17.73$)$ & $<0.01$ & 2.81 (1.57 to 5.04 ) & $<0.01$ \\
\hline Baseline NIHSS & 1.17 (1.04 to 1.32$)$ & 0.01 & 1.10 (0.99 to 1.23$)$ & 0.07 \\
\hline \multicolumn{5}{|l|}{ PSEl* $^{*}$} \\
\hline Lesion side, left & 1.16 (0.48 to 2.79 ) & 0.74 & 0.22 (0.06 to 0.85 ) & 0.03 \\
\hline Baseline PSEI & 4.93 (1.68 to 14.51$)$ & $<0.01$ & 4.84 (1.25 to 18.78$)$ & 0.02 \\
\hline Baseline NIHSS & 1.24 (1.07 to 1.43 ) & $<0.01$ & 1.19 (0.99 to 1.42$)$ & 0.06 \\
\hline \multicolumn{5}{|l|}{ Anger score $^{+}$} \\
\hline Age (yr) & $-0.14(-0.25$ to -0.02$)$ & 0.02 & $-0.08(-0.22$ to 0.05$)$ & 0.24 \\
\hline Female sex & $0.05(-0.11$ to 0.21$)$ & 0.54 & $-0.09(-0.27$ to 0.10$)$ & 0.38 \\
\hline Hypertension & $0.00(-0.11$ to 0.11$)$ & 0.97 & $0.10(-0.04$ to 0.23$)$ & 0.16 \\
\hline Hyperlipidemia & $-0.01(-0.12$ to 0.10$)$ & 0.85 & $0.11(-0.02$ to 0.24$)$ & 0.11 \\
\hline Smoking & $-0.01(-0.16$ to 0.15$)$ & 0.93 & $0.02(-0.16$ to 0.21$)$ & 0.80 \\
\hline Lesion side, left & $0.01(-0.10$ to 0.12$)$ & 0.83 & $-0.09(-0.22$ to 0.04$)$ & 0.17 \\
\hline Baseline anger score & 0.61 (0.49 to 0.72 ) & $<0.01$ & 0.20 (0.07 to 0.34$)$ & $<0.01$ \\
\hline Baseline NIHSS & $0.02(-0.09$ to 0.13$)$ & 0.76 & 0.14 (0.01 to 0.27 ) & 0.04 \\
\hline
\end{tabular}

Logistic regression test for binary variables (PSD, PSEI) and linear regression test for continuous variable (anger score). Beta refers to the standardized beta coefficient of the linear regression test. The PSD, PSEI, and anger score at 6 months post-stroke were used to identify significant factors.

PSD, post-stroke depression; PSEl, post-stroke emotional incontinence; LTP, long-term period; OR, odds ratio; Cl, confidence interval; NIHSS, National Institutes of Health Stroke Scale.

${ }^{*} \mathrm{OR} ;{ }^{+}$Beta.

significantly $(P<0.05)$ associated: baseline PSD and NIHSS for PSD at 6 months, hyperlipidemia and baseline PSD for PSD at LTP, baseline PSEI and NIHSS for PSEl at 6 months, left-side lesion and baseline PSEI at LTP, age and baseline anger score for PSA at 6 months, and baseline anger score and NIHSS for PSA at LTP (Table 3). There was no autocorrelation or multicollinearity in the multiple regression test.

Figure 3 shows the relationships of ESSI with MADRS and with anger score at LTP. The correlation test showed a significant negative relationship between MADRS and ESSI $(\rho=-$ $0.39, P<0.01)$ and between anger score and ESSI $(\rho=-0.28$, $P<0.01)$.

Table 4 shows the effect of low social support and mRS at LTP on PSD, PSEI, and anger scores at LTP. In the simple regression test, the effect of low social support and mRS on PSD was statistically significant. The significance remained in the multiple regression test after adjustment for age, sex, baseline PSD, baseline NIHSS, regular psychiatric clinic visits at LTP, antidepressant use at LTP, and recurrent stroke at LTP. However, the

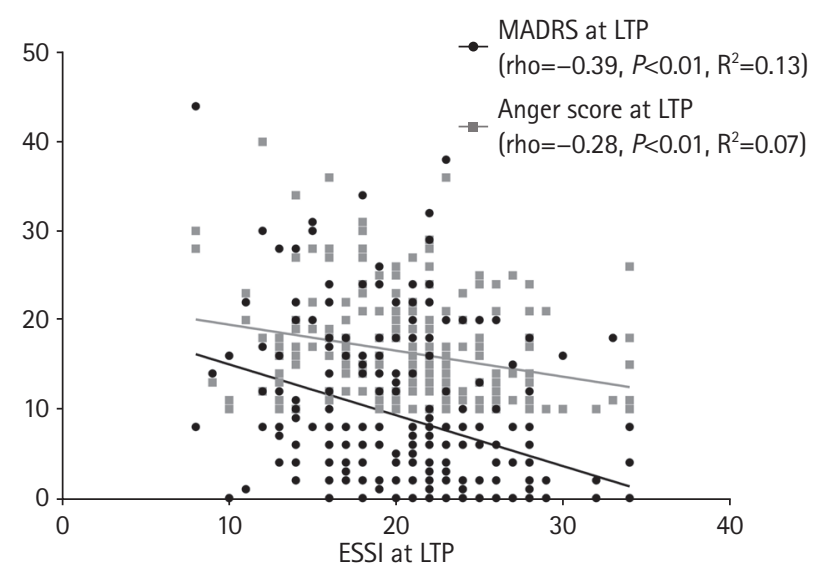

Figure 3. Correlation test results between Montgomery-Åsberg depression rating scale (MADRS) at long-term period (LTP) and enhancing recovery in coronary heart disease (ENRICHD) Social Support Instrument (ESSI), and between anger score at LTP and ESSI.

effect of low social support on PSD at LTP was greater than that of $\mathrm{mRS}$. There was no interaction between low social support and $m R S$ at $\operatorname{LTP}(P=0.53)$. Neither $m R S$ nor low social support 
Table 4. Simple and adjusted regression test of low social support and mRS at LTP, using PSD, PSEI, and anger score at LTP as outcomes

\begin{tabular}{|c|c|c|c|c|}
\hline \multirow{2}{*}{ Variable } & \multicolumn{2}{|c|}{ Simple test } & \multicolumn{2}{|c|}{ Adjusted test } \\
\hline & OR or beta $(95 \% \mathrm{Cl})$ & $P$ & OR or beta $(95 \% \mathrm{Cl})$ & $P$ \\
\hline \multicolumn{5}{|l|}{ PSD at LTP* } \\
\hline Age (yr) & & & 0.98 (0.95 to 1.01$)$ & 0.23 \\
\hline Female sex & & & 1.53 (0.74 to 3.18 ) & 0.25 \\
\hline Baseline PSD & & & 3.12 (1.56 to 6.24$)$ & $<0.01$ \\
\hline Baseline NIHSS & & & 0.90 (0.79 to 1.03$)$ & 0.13 \\
\hline Regular clinic visit & & & 3.50 (1.11 to 11.03$)$ & 0.03 \\
\hline Antidepressant use & & & 3.38 (1.02 to 11.18$)$ & 0.05 \\
\hline Recurrent stroke & & & 0.46 (0.09 to 2.42 ) & 0.36 \\
\hline $\mathrm{mRS}$ & 2.12 (1.67 to 2.70 ) & $<0.01$ & 2.16 (1.54 to 3.02 ) & $<0.01$ \\
\hline Low social support & 3.46 (1.94 to 6.16$)$ & $<0.01$ & 4.12 (1.97 to 8.66$)$ & $<0.01$ \\
\hline \multicolumn{5}{|l|}{ PSEl at LTP* } \\
\hline Age $(\mathrm{yr})$ & & & 0.98 (0.92 to 1.04$)$ & 0.47 \\
\hline Female sex & & & 1.51 (0.43 to 5.25$)$ & 0.52 \\
\hline Baseline PSEI & & & 3.94 (0.92 to 16.85$)$ & 0.06 \\
\hline Baseline NIHSS & & & 1.12 (0.90 to 1.40 ) & 0.32 \\
\hline MADRS at LTP & & & 1.07 (0.99 to 1.15 ) & 0.08 \\
\hline Regular clinic visit & & & 0.31 (0.03 to 3.61 ) & 0.35 \\
\hline Antidepressant use & & & 1.68 (0.34 to 8.22 ) & 0.52 \\
\hline Recurrent stroke & & & 0.52 (0.04 to 7.74$)$ & 0.64 \\
\hline $\mathrm{mRS}$ & 1.39 (0.95 to 2.04) & 0.09 & 0.96 (0.50 to 1.84$)$ & 0.90 \\
\hline Low social support & 3.63 (1.17 to 11.23$)$ & 0.03 & 2.01 (0.53 to 7.69$)$ & 0.31 \\
\hline \multicolumn{5}{|l|}{ Anger score at $\mathrm{LTP}^{+}$} \\
\hline Age (yr) & & & $-0.10(-0.23$ to 0.03$)$ & 0.14 \\
\hline Female sex & & & $-0.06(-0.18$ to 0.07$)$ & 0.38 \\
\hline Baseline anger score & & & 0.22 (0.10 to 0.34 ) & $<0.01$ \\
\hline Baseline NIHSS & & & $0.06(-0.07$ to 0.18$)$ & 0.39 \\
\hline MADRS & & & 0.45 (0.31 to 0.59$)$ & $<0.01$ \\
\hline Regular clinic visit & & & $0.11(-0.01$ to 0.23$)$ & 0.07 \\
\hline Antidepressant use & & & $0.04(-0.08$ to 0.17$)$ & 0.52 \\
\hline Recurrent stroke & & & $0.04(-0.07$ to 0.16$)$ & 0.48 \\
\hline $\mathrm{mRS}$ & $0.11(-0.02$ to 0.24$)$ & 0.10 & $-0.14(-0.30$ to 0.02$)$ & 0.09 \\
\hline Low social support & 0.25 (0.12 to 0.38$)$ & $<0.01$ & 0.14 (0.02 to 0.26$)$ & 0.03 \\
\hline
\end{tabular}

Logistic regression test for binary variables (PSD, PSEI) and linear regression test for continuous variable (anger score). Beta refers to the standardized beta coefficient of the linear regression test.

mRS, modified Rankin Scale; LTP, long-term period; PSD, post-stroke depression; PSEl, post-stroke emotional incontinence; OR, odds ratio; Cl, confidence interval; NIHSS, National Institutes of Health Stroke Scale; MADRS, Montgomery-Åsberg depression rating scale.

${ }^{*} \mathrm{OR}$; ${ }^{+}$Beta.

was significantly associated with PSEl at LTP. For PSA, the effect of low social support on the anger score at LTP was significant in the adjusted test. We additionally tested the relationship of ESSI or mRS with "PSD treatment" among patients with PSD at LTP. ESSI was positively associated with psychiatric clinic visits in the logistic regression test (odds ratio, 1.13; 95\% confidence interval, 1.02 to $1.25 ; P=0.03)$, while $\mathrm{mRS}$ was not $(P=0.11)$.

\section{Discussion}

To our knowledge, our study is the first to investigate the longterm (average 5 years) changes in PSD, PSEI, and PSA. We found that the prevalence of PSD and mean MADRS score gradually increased over time. We had previously found that the MADRS scores at the early stage of stroke decreased along 
with improvement in neurological deficits, probably due to psychological responses associated with improving neurological deficits. ${ }^{7}$ Our results are not consistent with a previous longitudinal study from the South London Stroke Register (SLSR). In this study, the prevalence of PSD defined by depression subscale score $>7$ in the Hospital Anxiety and Depression Scale was stationary over time: $33 \%$ (30\% to $36 \%$ ), $28 \%$ (25\% to $30 \%)$, and $31 \%$ (27\% to $34 \%)$ at 3 months, 1 year, and 5 years after stroke, respectively. ${ }^{17}$ Direct comparisons should be made cautiously because our study and the SLSR study are methodologically different. We conducted direct or phone interviews, whereas a postal interview was used in the SLSR study. While 222 of 356 patients (62.4\%) were followed up at LTP in our study, only 585 out of 3,689 (15.9\%) were followed up at 5 years in the SLSR study.

Nevertheless, the gradual increase in the degree and prevalence of PSD over time in our study needs to be discussed. Although $\mathrm{mRS}$ scores were still independent factors associated with PSD at LTP (Table 4), they gradually decreased over time in our study (Figure 2). Thus, the increasing prevalence of PSD at LTP is unlikely to be attributed to worsening functional disability. ${ }^{18}$ We found that low social support was significantly associated with PSD at LTP. Although we did not investigate ESSI at earlier time points, the strong relationship between ESSI and MADRS at LTP (Figure 3) suggests that the lack of social support may be one of the reasons for the persistent or increasing prevalence of PSD. We also found that only approximately 20\% of patients with PSD were under treatment. Although the treatment status was not described in the SLSR study, this factor may have contributed to the difference. In Korea, some depressive patients do not visit psychiatric clinics because of the social stigma attached to psychiatric diseases. ${ }^{19}$ More elderly Koreans regard depression as a "personal weakness" or "normal aging" instead of a "disease" than Americans. ${ }^{20}$ It was reported that the use of antidepressants in Korea was one of the lowest among OECD countries. ${ }^{21}$ All these factors may have contributed to the prevalent PSD at LTP in our cohort.

We noted that aside from baseline PSD and NIHSS scores, hyperlipidemia was a factor associated with PSD at LTP (Table 3). Although a study from Taiwan showed that patients with hyperlipidemia had a high risk of depression, ${ }_{1}^{22}$ a meta-analysis of the relationship between vascular risk factors and late-life depression did not show such an association. ${ }^{23}$ Further studies are required to confirm the relationship between PSD and hyperlipidemia.

We found that the prevalence and severity of PSEl decreased from 6 months post-stroke to LTP (Figure 2). This result was consistent with a report that revealed that the prevalence of
PSEI decreased from 21\% at 6 months post-stroke to $11 \%$ at 12 months post-stroke. ${ }^{24}$ Numerous studies have shown that PSEl is pathophysiologically closely associated with serotonergic system dysfunction in the brain in stroke patients. ${ }^{1,25-28}$ Thus, the decreasing prevalence of PSEI at LTP may be attributed to the recovery of the damaged serotonergic system in the brain over time. Unlike PSD, PSEI was not associated with ESSI in our study. The anger score also decreased from 6 months post-stroke to LTP (Figure 2). This may also be explained by the improved brain serotonergic system over time. However, unlike PSEl, the anger score was associated with low social support (Figure 3), although the relationship was not as strong as that with PSD. It has been shown that although PSA is closely associated with brain serotonergic system dysfunction, it is also related to depression and frustration. ${ }^{3}$

This study has a few limitations. First, since only Korean patients were enrolled, it may be difficult to apply the results to other ethnicities. Second, as we examined social support only once at LTP, its impact on patients' emotions at 6 months remains unknown. Third, we could not categorize lesion location precisely because the number of patients with PSD, PSEl, and high anger score were small. Fourth, since LTP was not pre-defined in this sub-study, the range of LTP was rather broad (35 to 85 months). Finally, many patients did not participate in the study. Compared with participants, non-participants were older and had higher initial MADRS and NIHSS scores (Table 1). In our study, multiple regression analysis showed that baseline PSD, but not MADRS score, was associated with PSD at LTP, and the initial NIHSS score was associated with PSA at LTP. Although it is difficult to precisely assess the possible impact of these differences on our results, the frequencies of post-stroke mood/emotional disturbances at LTP may have been underestimated in our study. This is an inherent problem in the research on depression; individuals with depression are more cautious and hesitant about clinical trial participation than those without. ${ }^{29}$ However, we do not think that this limitation greatly influenced our main findings, as our primary aim was to observe the long-term change in post-stroke emotional disorders rather than assess the exact prevalence of these symptoms in a certain period.

Despite these limitations, our data showed that the prevalence and degree of PSEI and anger score decreased, whereas those of PSD increased at LTP in our cohort. Our results have several practical implications. Physicians may consider cessation of medications for PSEl at LTP but need to be aware of the increased prevalence of PSD. As PSD and PSA are associated with a lack of social support, strategies to improve social support may have to be developed to prevent and manage PSD 
and PSA at LTP.

\section{Supplementary materials}

Supplementary materials related to this article can be found online at https://doi.org/10.5853/jos.2020.04637.

\section{Disclosure}

This work was supported by grants from Dong-A Pharmaceutical Company, who had no role in the design, analysis, interpretation, or publication of this study.

\section{References}

1. Kim JS, Choi S, Kwon SU, Seo YS. Inability to control anger or aggression after stroke. Neurology 2002;58:1106-1108.

2. Kim JS, Choi-Kwon S. Poststroke depression and emotional incontinence: correlation with lesion location. Neurology 2000;54:1805-1810.

3. Kim JS. Post-stroke mood and emotional disturbances: pharmacological therapy based on mechanisms. J Stroke 2016; 18:244-255.

4. Hackett ML, Pickles K. Part I: frequency of depression after stroke: an updated systematic review and meta-analysis of observational studies. Int J Stroke 2014;9:1017-1025.

5. Towfighi A, Ovbiagele B, El Husseini N, Hackett ML, Jorge RE, Kissela BM, et al. Poststroke depression: a scientific statement for healthcare professionals from the American Heart Association/American Stroke Association. Stroke 2017; 48:e30-e43.

6. Werheid K. A two-phase pathogenetic model of depression after stroke. Gerontology 2015;62:33-39.

7. Kim JS, Lee EJ, Chang DI, Park JH, Ahn SH, Cha JK, et al. Efficacy of early administration of escitalopram on depressive and emotional symptoms and neurological dysfunction after stroke: a multicentre, double-blind, randomised, placebo-controlled study. Lancet Psychiatry 2017;4:33-41.

8. Montgomery SA, Asberg M. A new depression scale designed to be sensitive to change. BrJ Psychiatry 1979;134:382-389.

9. Kearns NP, Cruickshank CA, McGuigan KJ, Riley SA, Shaw SP, Snaith RP. A comparison of depression rating scales. BrJ Psychiatry 1982;141:45-49.

10. Kang HJ, Stewart R, Kim JM, Jang JE, Kim SY, Bae KY, et al. Comparative validity of depression assessment scales for screening poststroke depression. J Affect Disord 2013;147: 186-191.

11. Lee EJ, Kim JS, Chang DI, Park JH, Ahn SH, Cha JK, et al. Dif- ferences in therapeutic responses and factors affecting poststroke depression at a later stage according to baseline depression. J Stroke 2018;20:258-267.

12. Brott $T$, Adams HP Jr, Olinger $C P$, Marler JR, Barsan WG, Biller $J$, et al. Measurements of acute cerebral infarction: a clinical examination scale. Stroke 1989;20:864-870.

13. Farrell B, Godwin J, Richards S, Warlow C. The United Kingdom transient ischaemic attack (UK-TIA) aspirin trial: final results. J Neurol Neurosurg Psychiatry 1991;54:1044-1054.

14. Rao N. The clinical pharmacokinetics of escitalopram. Clin Pharmacokinet 2007:46:281-290.

15. Mitchell PH, Powell L, Blumenthal J, Norten J, Ironson G, Pitula $C R$, et al. A short social support measure for patients recovering from myocardial infarction: the ENRICHD Social Support Inventory. J Cardiopulm Rehabil 2003;23:398-403.

16. ENRICHD Investigators. Enhancing recovery in coronary heart disease (ENRICHD): baseline characteristics. Am J Cardiol 2001;88:316-322.

17. Ayerbe L, Ayis $S$, Rudd AG, Heuschmann PU, Wolfe CD. Natural history, predictors, and associations of depression 5 years after stroke: the South London Stroke Register. Stroke 2011;42:1907-1911.

18. Ayerbe $L$, Ayis $S$, Crichton $S$, Wolfe CD, Rudd AG. The longterm outcomes of depression up to 10 years after stroke: the South London Stroke Register. J Neurol Neurosurg Psychiatry 2014;85:514-521.

19. Ki M, Paik JW, Choi KS, Ryu SH, Han C, Lee K, et al. Delays in depression treatment among Korean population. Asia Pac Psychiatry 2014;6:414-424.

20. Turvey CL, Jogerst G, Kim MY, Frolova E. Cultural differences in depression-related stigma in late-life: a comparison between the USA, Russia, and South Korea. Int Psychogeriatr 2012;24:1642-1647.

21. Organization for Economic Cooperation. Health at a glance 2015: OECD indicators. Paris: OECD; 2015.

22. Chuang $\mathrm{CS}$, Yang TY, Muo $\mathrm{CH}$, Su HL, Sung $\mathrm{FC}$, Kao CH. Hyperlipidemia, statin use and the risk of developing depression: a nationwide retrospective cohort study. Gen Hosp Psychiatry 2014;36:497-501.

23. Valkanova V, Ebmeier KP. Vascular risk factors and depression in later life: a systematic review and meta-analysis. Biol Psychiatry 2013;73:406-413.

24. House A, Dennis M, Molyneux A, Warlow C, Hawton K. Emotionalism after stroke. BMJ 1989;298:991-994.

25. Andersen $G$, Ingeman-Nielsen $M$, Vestergaard $K$, Riis JO. Pathoanatomic correlation between poststroke pathological crying and damage to brain areas involved in serotonergic neurotransmission. Stroke 1994:25:1050-1052. 
26. Kim JM, Stewart R, Kang HJ, Bae KY, Kim SW, Shin IS, et al. Associations of serotonergic genes with poststroke emotional incontinence. Int J Geriatr Psychiatry 2012;27:799-806.

27. Kim JS. Post-stroke emotional incontinence after small lenticulocapsular stroke: correlation with lesion location. J Neurol 2002;249:805-810.
28. Murai T, Barthel H, Berrouschot J, Sorger D, von Cramon DY, Müller U. Neuroimaging of serotonin transporters in poststroke pathological crying. Psychiatry Res 2003;123:207-211.

29. Leykin Y, Dunn LB, Muñoz RF. The effect of depression on the decision to join a clinical trial. J Consult Clin Psychol 2017; 85:751-756. 
Supplementary Table 1. Criteria for post-stroke emotional incontinence and anger used in this study

\begin{tabular}{|c|c|c|}
\hline & Original definition & Modified ${ }^{*}$ \\
\hline $\begin{array}{l}\text { Kim's criteria for post-stroke } \\
\text { emotional incontinence (PSEI) }\end{array}$ & $\begin{array}{l}\text { Patients and relatives were asked if the patient showed excessive or inappropriate } \\
\text { laughing, crying, or both, as compared with the premorbid state. } \\
\text { PSEl was confirmed when both the patient and relatives agree that they occurred } \\
\text { on more than two occasions. } \\
\text { Inappropriateness indicates laughing or crying that occurs while talking, listening, } \\
\text { meeting people, or watching television, when the incident is not particularly } \\
\text { amusing or sad to ordinary people. }\end{array}$ & $\begin{array}{l}\text { Same as the original definition, } \\
\text { but relative's confirmation was } \\
\text { not required }\end{array}$ \\
\hline $\begin{array}{l}\text { Spielberger trait anger-Kim's scale } \\
\text { for post-stroke anger (PSA) }\end{array}$ & $\begin{array}{l}\text { Assessment of PSA }{ }^{+} \text {was supported by application of the } 10 \text {-item Spielberger } \\
\text { Trait Anger Scale. } \\
\text { For each question, patients were asked to use a numerical scale }(1, \text { almost never; } 2 \text {, } \\
\text { sometimes; } 3 \text {, often; and } 4 \text {, almost always) to best represent their pre-stroke and } \\
\text { current (post-stroke) statuses, separately. An overall anger score was obtained by } \\
\text { summation of individual scores. PSA was defined to be present when (1) the sum } \\
\text { of the PSA score was higher than that of pre-stroke score; }(2) \text { the patient felt that } \\
\text { he or she had developed PSA; and (3) at least one of the relatives who lived with } \\
\text { the patient agreed on number } 2 \text {. }\end{array}$ & $\begin{array}{l}\text { Same as the original definition, } \\
\text { but relative's confirmation was } \\
\text { not required and the PSA was not } \\
\text { compared with the pre-stroke } \\
\text { score. }\end{array}$ \\
\hline
\end{tabular}

*Originals were modified for clinical trials. By omitting "relative's confirmation" we were able to include patients who lived alone and could more easily perform telephone or postal interview. We were also able to decrease the burden on investigators and patients in the trial; 'The term "inability to control anger and aggression" was used in the original paper. 